\title{
Chronic endometritis and infertility
}

\author{
Hyun Jong Park', You Shin Kim², Tae Ki Yoon², Woo Sik Lee ${ }^{2}$ \\ ${ }^{1}$ Department of Obstetrics and Gynecology, Fertility Center of CHA Gumi Medical Center, CHA University, Gumi; ${ }^{2}$ Department of Obstetrics and \\ Gynecology, Fertility Center of CHA Gangnam Medical Center, CHA University, Seoul, Korea
}

Chronic endometritis (CE) is a condition involving the breakdown of the peaceful co-existence between microorganisms and the host immune system in the endometrium. A majority of CE cases produce no noticeable signs or mild symptoms, and the prevalence rate of CE has been found to be approximately $10 \%$. Gynecologists and pathologists often do not focus much clinical attention on CE due to the time-consuming microscopic examinations necessary to diagnose CE, its mild clinical manifestations, and the benign nature of the disease. However, the relationship between CE and infertility-related conditions such as repeated implantation failure and recurrent miscarriage has recently emerged as an area of inquiry. In this study, we reviewed the literature on the pathophysiology of CE and how it may be associated with infertility, as well as the literature regarding the diagnosis and treatment of CE. In addition, we discuss the value of hysteroscopic procedures in the diagnosis and treatment of CE.

Keywords: Chronic endometritis; Endometrium; Fertilization in vitro; Hysteroscopy; Repeated implantation failure

\section{Introduction}

Chronic endometritis (CE) is generally asymptomatic or has vague symptoms, such as abnormal uterine bleeding, pelvic pain, and leukorrhea [1]. The research has shown the prevalence rate of CE to be approximately $10 \%$ to $11 \%$ based on biopsies of patients who underwent hysterectomies due to benign gynecologic conditions [2,3]. Gynecologists and pathologists often do not focus much clinical attention on CE due to the time-consuming microscopic examinations necessary to diagnose $C E$, its mild clinical manifestations, and the benign nature of the disease [4,5]. However, the possible relationship of CE with infertility and/or perinatal complications has recently emerged as an area of ongoing research [6].

In fact, Romero et al. [7] reported that $15 \%$ of infertile women who underwent in vitro fertilization (IVF) cycles had CE, and the preva-

Received: May 19, 2016 · Revised: Jun 9, 2016 · Accepted: Jun 30, 2016 Corresponding author: Woo Sik Lee

Department of Obstetrics and Gynecology, Fertility Center of CHA Gangnam Medical Center, CHA University, 566 Nonhyeon-ro, Gangnam-gu, Seoul 06135, Korea

Tel: +82-2-3468-2840 Fax: +82-2-3468-2610 E-mail: wooslee@cha.ac.kr

This is an Open Access article distributed under the terms of the Creative Commons Attribution Non-Commercial License (http://creativecommons.org/licenses/by-nc/4.0/) which permits unrestricted non-commercial use, distribution, and reproduction in any medium, provided the original work is properly cited. lence rate of $C E$ was as high as $42 \%$ in patients with recurrent implantation failure (RIF). Zolghadri et al. [8] also reported CE findings on hysteroscopy in $57.8 \%$ of women with a past history of three or more recurrent pregnancy losses (RPLs). According to a recent prospective study of patients with RIF or RPL, the CE prevalence rate in the RIF group was $14 \%$ (six of 43 ) and $27 \%$ in the RPL group (14 of 51) [9]. Considering these results, CE may be a gynecologic condition that must not be ignored in the context of assisted reproductive treatment (ART). In this study, we reviewed the literature on the relationship between CE and infertility-related conditions, such as RPL, RIF and other reproductive outcomes, that had been published on PubMed as of January 2016.

\section{Diagnosis of CE}

Usually, CE is diagnosed by endometrial biopsy, and the presence of plasma cells in the endometrial stroma is the generally accepted histological diagnostic criterion for CE [2,10]. However, the accuracy of histological diagnoses can be compromised by conditions such as mononuclear inflammatory cell infiltration, stromal cell proliferation, a plasmacytoid appearance of stromal cells, or a pronounced pre-decidual reaction in the late secretory endometrium (EM). Therefore, the rate of misdiagnosis may be higher than ideal [1,11-13]. Furthermore, 
the histological detection of $\mathrm{CE}$ is time-consuming and difficult.

Hematoxylin and eosin (H\&E) staining in women with infertility and patients with a history of repeated spontaneous miscarriages had a low diagnostic rate $(<10 \%)[10,14]$. Recently, an immunohistochemical (IHC) stain capable of detecting CD38 and CD138 plasma cellspecific surface antigens was introduced for the confirmation of the presence of plasma cells inside the EM [15]. In women with a history of RPL, IHC staining for CD138 showed a dramatically higher sensitivity for diagnosing $\mathrm{CE}$, with values as high as $56 \%$, as compared to a $13 \%$ sensitivity for H\&E staining [16]. Furthermore, additional IHC staining for CD138 in H\&E-stained tissue specimens increased the diagnostic concordance between pathologists [11].

The diagnostic difficulties posed by CE as well as the relatively low clinical effectiveness of pathological diagnoses of CE have been considered problems. In fact, plasma cell endometritis was found to have no correlation with bacterial colonization of the EM or the clinical presentation of pelvic inflammatory disease (PID) $[17,18]$. In actual cases, plasma cell endometritis was histologically diagnosed in 39\% of women who underwent an endometrial biopsy, but as many as $82 \%$ of women had positive findings in microbial cultures of EM biopsy samples. Haggerty et al. [19] reported that histologic endometritis showed no association with reproductive morbidity in randomized controlled trials (RCTs) of antibiotics in patients with clinical PID symptoms. These findings suggested that the histological diagnosis of CE could not determine which patients could benefit from further antibiotic treatment in terms of fertility-related outcomes.

Fluid hysteroscopy is another powerful tool for diagnosing CE $[20,21]$. The diagnostic findings of CE from fluid hysteroscopy include micropolyps, stromal edema, and focal or diffuse hyperemia (Figure

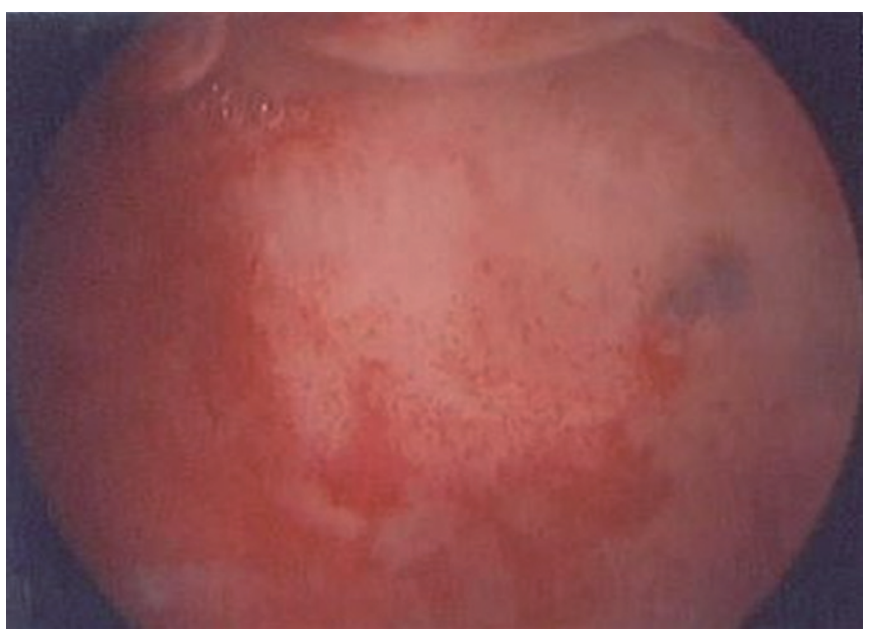

Figure 1. Hysteroscopic finding of chronic endometritis. The focal hyperemic area allowed chronic endometritis to be diagnosed in a woman with a history of repeated implantation failure (photo courtesy of HJ Park, MD).
1). The hysteroscopic evaluation of endometrial inflammatory disease showed a much greater sensitivity for detecting CE than endometrial cultures [22]. Even when compared with the histologic diagnosis of CE, fluid hysteroscopy showed a very high diagnostic accuracy $(93.4 \%)$ [20,21,23]. Discrepancies between hysteroscopic findings and histologic observations may be due to the many limitations involved in the histologic diagnosis of CE [13].

A normal EM pattern observed in hysteroscopy was a relatively accurate predictor of successful pregnancy after ART [22]. In a retrospective study including patients with unexplained RPL, the patients in whom hysteroscopic findings normalized after antibiotic treatment for $C E$, regardless of the results of endometrial cultures, showed a significantly higher incidence of successful pregnancy than the patients who did not show normalization [24]. Considering the link between hysteroscopic CE findings and poor reproductive outcomes, the difficulties involved in the pathological diagnosis of $\mathrm{CE}$, and the discrepancy between pathological and hysteroscopic findings, hysteroscopic evaluation of the endometrial cavity should be considered as a regular test in clinical practice in the assessment of patients with RIF or RPL [24,25].

\section{Pathophysiology of CE}

\section{Host and microorganisms}

Conventionally, the uterine cavity is assumed to be sterile, but in fact, microorganisms have been detected in the endometrial cavity of non-pregnant women [26-29].

It has been proposed that microorganisms ascending from the lower genital tract could colonize the uterine cavity; however, host mechanisms have been expected to restrict bacterial proliferation and invasion [26-30]. These mechanisms involve the cervical mucus plug [31-34], the endometrial epithelium and its immune cellular components (neutrophils, macrophages, and natural killer cells), and elements of the innate immune system, including natural antimicrobial peptides present in the EM [32,35-37]. An appropriate and balanced acute inflammatory process has been shown to play a major role in the eradication of microbial invasions [38].

Microorganisms form biofilms (i.e., matrices of polymeric compounds) as strategies against host immune mechanisms as well as against natural and synthetic antibiotics $[39,40]$. In fact, chronic infections such as valvular endocarditis, otitis media, chronic bacterial prostatitis, and periodontitis have been associated with the presence of bacterial biofilms, which contribute to subclinical colonization of the uterine cavity [41-47].

Interactions between infectious agents and the endometrial environment are a major concern in the treatment of infertility, miscarriage, and preterm labor [48]. In septic conditions, microorganisms 
are only a part of the problem; sepsis also involves problems in inflammatory control and/or the anti-inflammatory response of the host [49]. In a study of the mechanisms involved in preterm labor, the microorganisms present on the endometrial surface were not found to induce a pro-inflammatory response, and maintained peaceful coexistence with the host during the course of normal pregnancies [40,50-54]. However, if the host (mother, embryo/fetus, or both) became aware of the microorganisms via pattern-recognition receptors and initiated a pro-inflammatory response, peaceful co-existence was no longer possible. Changes in virulence patterns, such as planktonic bacteria released from biofilms, also caused a change in the balance between microorganisms and the host, resulting in inflammation-induced preterm parturition.

\section{Normal-pattern pregnancies and other background information}

Inflammatory mediators in the EM, including leukocytes, immunoglobulins, and cytokines, have been found to play very important roles in regulating the immune response and trophoblast growth in implantation [7]. The EM was found to be physiologically colonized by a pleiotrophic population of immune-competent cells [55]. These immune-competent cells controlled local defenses and modulated the host reaction to the embryo, ultimately assisting in the implantation of the embryo and the maintenance of pregnancy. Successful implantation of the embryo and maintenance of the pregnancy were the result of a delicate balance between the embryo and the EM, reflecting the prevalence of a $\mathrm{TH} 2$ versus a $\mathrm{TH} 1$ cytokine profile in the EM. Therefore, any conditions that disturb this balance could damage endometrial receptivity.

Various immune-competent cells of the EM have been found to secrete chemokines, attracting natural killer (NK) cells and macrophages from the circulating peripheral blood toward the EM [56-59]. In addition, trophoblasts facilitated pro-inflammatory cytokine production from the recruited monocytes and macrophages, which had a significant role in implantation and placental formation [58].

An increase in the amount of NK cells in peripheral blood drove the cytokine balance to favor the $\mathrm{TH} 1$ pathway $[55,60]$. This is likely to have negative effects on trophoblast invasion and implantation, consequently increasing the possibility for early pregnancy loss.

\section{Chronic endometritis}

In CE, endometrial receptivity decreases through mechanisms other than an increase in the percentage of NK cells. In fact, the secretory EM of patients with CE was found to show significantly lower percentages of CD56+ CD16- cells and CD56 bright CD16- cells than was observed in patients without CE ( $47.8 \%$ vs. $30.1 \%$ and $79.5 \%$ vs. $67.3 \%, p<0.01)[60]$. The secretory EM of the CE group showed a sig- nificantly higher percentage of $\mathrm{CD} 3+$ cells than the secretory $\mathrm{EM}$ of patients without CE ( $25 \%$ vs. $10.5 \%, p<0.01)$. Additionally, in micropolypoid EM samples in patients with CE, the low endometrial NK cell density facilitated the survival of residual endometrial cells, possibly resulting in the development of mucosal polyps [61]. Kitaya and Yasuo [2] reported that lymphocyte B cell levels were elevated in the $E M$ of patients with $C E$, as well as observing the abnormal expression of paracrine mediators such as adhesion molecules and chemokines. In fact, the menstrual effluent of women with CE showed elevated pro-inflammatory cytokine levels, including interleukin (IL)-6, IL-1 $\beta$, and tumor necrosis factor $\alpha$, in comparison to women without $C E$; these findings were argued to reflect a $\mathrm{TH} 1 / \mathrm{TH} 2$ cytokine imbalance at the EM level [62].

Infection is the basis of CE. Cicinelli et al. [21] analyzed 438 cases of hysteroscopically diagnosed $C E$, and reported that $73.1 \%$ exhibited $\geq 1$ positive pathogen finding. Most endometrial infections were common bacterial infections (58\%), including Gram-negative bacteria, and Ureaplasma urealyticum was found in $10 \%$ of cases. Chlamydia was found in $2.7 \%$ of cases. Gram-negative bacterial colonization of the EM may lower the implantation rate of embryos while increasing the rate of miscarriage. The endotoxins of Gram-negative bacteria may induce a more predominant $\mathrm{TH} 1$ response at the decidua in order to stimulate pro-inflammatory cytokine production, thereby creating an endometrial paracrine milieu that could cause embryo damage, implantation failure, or spontaneous abortion $[62,63]$. Female genital tuberculosis can cause CE and infertility. It is uncommon in developed countries, and is associated with predisposing factors such as poverty, ill health, and immune suppression [64]. In addition, it is a secondary form of tuberculosis, mainly originating from pulmonary tuberculosis, so rare cases of solitary tuberculous endometritis may have occurred due to female genital tuberculosis spreading to the neighboring viscus [65]. We excluded tuberculous endometritis from the discussion of this article.

In EM with CE, the IGFBP1 gene was upregulated, whereas genes such as IGF1, IL-11, and CCL4 were downregulated [66]. IGF1 mediated the effect of estrogen on endometrial proliferation, while IGF2 mediated the effect of progesterone during the secretory phase by facilitating the implantation and invasion of embryos $[59,67,68]$. IGFBP1 was secreted from endometrial stromal cells during the process of decidualization, exerting negative effects on the implantation process of the embryo and counteracting the effect of IGF2. Increased IGFBP1 gene expression and reduction in IGF1 gene expression in EM with CE resulted in unfavorable conditions for implantation and embryo development.

IL-11 is a cytokine with anti-inflammatory properties. Its production was found to be greatest during decidualization $[69,70]$. Inappropriate IL-11 signaling resulted in dysregulation with respect to trophoblast 
invasion [56,71,72]; therefore, IL-11 downregulation in EM with CE at the implantation window was strongly associated with infertility.

During the early stage of pregnancy, trophoblasts were found to recruit NK cells and macrophages into the EM through chemokines such as CCL4 and to stimulate them to produce pro-inflammatory cytokines [56-59]. Downregulated CCL4 activity due to CE could result in the failure of implantation or abnormal placental formation.

In summary, chronic endometrial inflammation can alter endometrial cytokine production, damage endometrial function [73], result in the formation of abnormal patterns of lymphocyte subsets in the $\mathrm{EM}$, and induce the altered secretion of paracrine factors, which ultimately may reduce the receptivity of embryos in the $\mathrm{EM}[60,66]$. In fact, delayed differentiation of the EM in the mid-secretory phase (out-of-phase morphology) was observed in cases of CE [74]. The proliferative phenotype of the EM was found in cases of CE even during the secretory phase, due to an increase in estrogen receptors and cell proliferation-associated nuclear marker Ki-67 expression [75,76].

\section{Treatment of CE}

Doxycycline, a broad-spectrum antibiotic effective against organisms ranging from common bacteria to mycoplasma, is often used to treat CE [77]. Antibiotic treatment has been found to be relatively effective for CE. Johnston-MacAnanny et al. [78] showed that $70 \%$ of cases of CE demonstrated in EM biopsies were cured by a regimen of $100 \mathrm{mg}$ of doxycycline twice per day for 14 days. Kitaya et al. [79] also reported that the histological clearance rate of CD138+ plasma cells on the EM of RIF patients with CE was up to $96 \%$ using the above doxycycline-only regimen. The histopathologic cure rate of CE using a combination of ofloxacin (400 mg twice per day for 14 days) and metronidazole (500 mg twice per day for 14 days) was 73\% [14].

Antibiotic treatment may attenuate the effect of CE on infertility. In a retrospective analysis of patients with unexplained RPL and CE findings on diagnostic hysteroscopy, Cicinelli et al. [24] reported that the clinical pregnancy rate of the group whose hysteroscopic findings normalized 1 year after antibiotic treatment was significantly higher than that of the non-normalized group (74.8\% [88 of 118] vs. $24.4 \%$ [22 of 90]). The prospective study of McQueen et al. [14] showed that the per-pregnancy live birth rate in RPL patients with CE significantly increased to as high as $56 \%$ after antibiotic treatment, compared to $7 \%$ before treatment.

Studies have been carried out on RIF patients with CE undergoing in vitro fertilization-embryo transfer (IVF-ET) cycles. According to the retrospective study of Yang et al. [25], the implantation rate (18.6\% [18 of 97] vs. 4.9\% [3 of 61]) and the ongoing pregnancy rate $(29.3 \%$ [12 of 41] vs. 7.4\% [2/27]) in IVF-ET cycles significantly increased after antibiotic treatment, in comparison to pre-treatment outcomes. Cici- nelli et al. [22] conducted a retrospective study of RIF patients undergoing fresh IVF-ET cycles, and found that the clinical pregnancy rate and the live birth rate in the group with normal hysteroscopic findings after antibiotic treatment were significantly higher than in the group with consistent CE findings (65\% vs. $33 \%$ and $60.8 \%$ vs. $13.3 \%$, respectively). The above results suggest that CE plays a significant role in infertility.

In this article, we discussed the value of diagnostic hysteroscopy in the treatment of CE. Some studies have proposed that endometrial scratching or injury, as is involved in diagnostic hysteroscopy, could increase the implantation rate and the clinical pregnancy rate in women with previous IVF-ET failures [80-85]. The hypothetical biological basis for this proposal is as follows [86]. First, a topical injury in the EM could increase the implantation rate, leading to decidualization. Second, cytokines and growth hormone secreted during the recovery process after an artificial injury to the EM could have good effects on the embryo implantation. Third, an artificial injury to the EM could delay the earlier maturation of the EM attributable to hyperstimulated ovaries in the next IVF-ET cycle.

In this article, we would like to propose an additional hypothesis regarding CE. Hysteroscopy may be a powerful tool for physically removing bacterial biofilms in the EM that contribute to the pathophysiology of CE. Finally, as latent CE in patients with RIF can improve after hysteroscopy, reproductive outcomes in subsequent IVF-ET cycles may also improve. Currently, limited evidence supports this proposal. Recent meta-analyses $[87,88]$ concerning hysteroscopy or artificial endometrial injuries in ART have reported significant improvements in the clinical pregnancy rate. However, this possibility has yet to be supported by well-designed RCTs, so this proposal must remain hypothetical for the time being.

\section{Conclusions}

So far, CE has been considered insignificant in gynecologic clinical practice. However, it is has been associated with poor reproductive outcomes in the context of ART. In cases of CE, the peaceful co-existence between the host immunity and microorganisms breaks down, the distribution of lymphocytes involved in the implantation of embryos is altered, and ultimately, EM receptivity is reduced due to the inadequate secretion of various cytokines. Recent clinical studies in patients with RPL or RIF showed that antibiotic treatment for CE could produce dramatic changes in future pregnancy outcomes $[14,22,24,25]$. Our review article attempted to evaluate the benefits of hysteroscopic procedures in the diagnosis and treatment of latent CE as an addition to extant theories. However, due to the lack of high-quality evidence in the published literature, such proposals must remain hypothetical. Therefore, well-designed prospective 
studies or RCTs should be conducted in order to clarify possible correlations between $\mathrm{CE}$ and poor reproductive outcomes as well as the efficacy of endometrial interventions.

\section{Conflict of interest}

No potential conflict of interest relevant to this article was reported.

\section{References}

1. Greenwood SM, Moran JJ. Chronic endometritis: morphologic and clinical observations. Obstet Gynecol 1981;58:176-84.

2. Kitaya K, Yasuo T. Immunohistochemistrical and clinicopathological characterization of chronic endometritis. Am J Reprod Immunol 2011;66:410-5.

3. Polisseni F, Bambirra EA, Camargos AF. Detection of chronic endometritis by diagnostic hysteroscopy in asymptomatic infertile patients. Gynecol Obstet Invest 2003;55:205-10.

4. Bayer-Garner IB, Korourian S. Plasma cells in chronic endometritis are easily identified when stained with syndecan-1. Mod Pathol 2001;14:877-9.

5. Yorukoglu K, Kuyucouglu F. Chronic nonspecific endometritis. Gen Diagn Pathol 1998;143:287-90.

6. Kitaya K, Matsubayashi H, Yamaguchi K, Nishiyama R, Takaya Y, Ishikawa T, et al. Chronic endometritis: potential cause of infertility and obstetric and neonatal complications. Am J Reprod Immunol 2016;75:13-22.

7. Romero R, Espinoza J, Mazor M. Can endometrial infection/inflammation explain implantation failure, spontaneous abortion, and preterm birth after in vitro fertilization? Fertil Steril 2004;82: 799-804.

8. Zolghadri J, Momtahan M, Aminian K, Ghaffarpasand F, Tavana Z. The value of hysteroscopy in diagnosis of chronic endometritis in patients with unexplained recurrent spontaneous abortion. Eur J Obstet Gynecol Reprod Biol 2011;155:217-20.

9. Bouet PE, El Hachem H, Monceau E, Gariepy G, Kadoch IJ, Sylvestre C. Chronic endometritis in women with recurrent pregnancy loss and recurrent implantation failure: prevalence and role of office hysteroscopy and immunohistochemistry in diagnosis. Fertil Steril 2016;105:106-10.

10. Kasius JC, Fatemi HM, Bourgain C, Sie-Go DM, Eijkemans RJ, Fauser $\mathrm{BC}$, et al. The impact of chronic endometritis on reproductive outcome. Fertil Steril 2011;96:1451-6.

11. Kasius JC, Broekmans FJ, Sie-Go DM, Bourgain C, Eijkemans MJ, Fauser $\mathrm{BC}$, et al. The reliability of the histological diagnosis of endometritis in asymptomatic IVF cases: a multicenter observer study. Hum Reprod 2012;27:153-8.
12. Crum CP, Egawa K, Fenoglio CM, Richart RM. Chronic endometritis: the role of immunohistochemistry in the detection of plasma cells. Am J Obstet Gynecol 1983;147:812-5.

13. Adegboyega PA, Pei Y, McLarty J. Relationship between eosinophils and chronic endometritis. Hum Pathol 2010;41:33-7.

14. McQueen DB, Bernardi LA, Stephenson MD. Chronic endometritis in women with recurrent early pregnancy loss and/or fetal demise. Fertil Steril 2014;101:1026-30.

15. Bayer-Garner IB, Nickell JA, Korourian S. Routine syndecan-1 immunohistochemistry aids in the diagnosis of chronic endometritis. Arch Pathol Lab Med 2004;128:1000-3.

16. McQueen DB, Perfetto CO, Hazard FK, Lathi RB. Pregnancy outcomes in women with chronic endometritis and recurrent pregnancy loss. Fertil Steril 2015;104:927-31.

17. Andrews WW, Goldenberg RL, Hauth JC, Cliver SP, Conner M, Goepfert AR. Endometrial microbial colonization and plasma cell endometritis after spontaneous or indicated preterm versus term delivery. Am J Obstet Gynecol 2005;193:739-45.

18. Korn AP, Hessol N, Padian N, Bolan G, Muzsnai D, Donegan E, et al. Commonly used diagnostic criteria for pelvic inflammatory disease have poor sensitivity for plasma cell endometritis. Sex Transm Dis 1995;22:335-41.

19. Haggerty CL, Ness RB, Amortegui A, Hendrix SL, Hillier SL, Holley $\mathrm{RL}$, et al. Endometritis does not predict reproductive morbidity after pelvic inflammatory disease. Am J Obstet Gynecol 2003; 188:141-8.

20. Cicinelli E, Resta L, Nicoletti R, Zappimbulso V, Tartagni M, Saliani $\mathrm{N}$. Endometrial micropolyps at fluid hysteroscopy suggest the existence of chronic endometritis. Hum Reprod 2005;20:1386-9.

21. Cicinelli E, De Ziegler D, Nicoletti R, Colafiglio G, Saliani N, Resta L, et al. Chronic endometritis: correlation among hysteroscopic, histologic, and bacteriologic findings in a prospective trial with 2190 consecutive office hysteroscopies. Fertil Steril 2008;89:67784.

22. Cicinelli E, Matteo M, Tinelli R, Lepera A, Alfonso R, Indraccolo U, et al. Prevalence of chronic endometritis in repeated unexplained implantation failure and the IVF success rate after antibiotic therapy. Hum Reprod 2015;30:323-30.

23. Cicinelli E, Tinelli R, Lepera A, Pinto V, Fucci M, Resta L. Correspondence between hysteroscopic and histologic findings in women with chronic endometritis. Acta Obstet Gynecol Scand 2010;89: 1061-5.

24. Cicinelli E, Matteo M, Tinelli R, Pinto V, Marinaccio M, Indraccolo $\mathrm{U}$, et al. Chronic endometritis due to common bacteria is prevalent in women with recurrent miscarriage as confirmed by improved pregnancy outcome after antibiotic treatment. Reprod Sci 2014;21:640-7. 
25. Yang R, Du X, Wang Y, Song X, Yang Y, Qiao J. The hysteroscopy and histological diagnosis and treatment value of chronic endometritis in recurrent implantation failure patients. Arch Gynecol Obstet 2014;289:1363-9.

26. Nelson LH, Nichols SB. Effectiveness of the Isaacs cell sampler for endometrial cultures. J Reprod Med 1986;31:473-7.

27. Ansbacher R, Boyson WA, Morris JA. Sterility of the uterine cavity. Am J Obstet Gynecol 1967;99:394-6.

28. Cowling P, McCoy DR, Marshall RJ, Padfield CJ, Reeves DS. Bacterial colonization of the non-pregnant uterus: a study of premenopausal abdominal hysterectomy specimens. Eur J Clin Microbiol Infect Dis 1992;11:204-5.

29. Moller BR, Kristiansen FV, Thorsen P, Frost L, Mogensen SC. Sterility of the uterine cavity. Acta Obstet Gynecol Scand 1995;74:2169.

30. Simhan HN, Caritis SN, Krohn MA, Hillier SL. Elevated vaginal pH and neutrophils are associated strongly with early spontaneous preterm birth. Am J Obstet Gynecol 2003;189:1150-4.

31. Zuckerman H, Kahana A, Carmel S. Antibacterial activity of human cervical mucus. Gynecol Invest 1975;6:265-71.

32. Svinarich DM, Wolf NA, Gomez R, Gonik B, Romero R. Detection of human defensin 5 in reproductive tissues. Am J Obstet Gynecol 1997;176:470-5.

33. Hein M, Helmig RB, Schonheyder HC, Ganz T, Uldbjerg N. An in vitro study of antibacterial properties of the cervical mucus plug in pregnancy. Am J Obstet Gynecol 2001;185:586-92.

34. Hein M, Valore EV, Helmig RB, Uldbjerg N, Ganz T. Antimicrobial factors in the cervical mucus plug. Am J Obstet Gynecol 2002; 187:137-44.

35. Quayle AJ, Porter EM, Nussbaum AA, Wang YM, Brabec C, Yip KP, et al. Gene expression, immunolocalization, and secretion of human defensin-5 in human female reproductive tract. Am J Pathol 1998;152:1247-58.

36. King AE, Critchley HO, Kelly RW. Innate immune defences in the human endometrium. Reprod Biol Endocrinol 2003;1:116.

37. King AE, Fleming DC, Critchley HO, Kelly RW. Differential expression of the natural antimicrobials, beta-defensins 3 and 4 , in human endometrium. J Reprod Immunol 2003;59:1-16.

38. Profet M. Menstruation as a defense against pathogens transported by sperm. Q Rev Biol 1993;68:335-86.

39. Donlan RM. Role of biofilms in antimicrobial resistance. ASAIO J 2000;46:S47-52.

40. Donlan RM, Costerton JW. Biofilms: survival mechanisms of clinically relevant microorganisms. Clin Microbiol Rev 2002;15:16793.

41. Costerton W, Veeh R, Shirtliff M, Pasmore M, Post C, Ehrlich G. The application of biofilm science to the study and control of chronic bacterial infections. J Clin Invest 2003;112:1466-77.

42. Stepanovic S, Jovanovic M, Lavadinovic L, Stosovic B, Pelemis M. Enterococcus durans endocarditis in a patient with transposition of the great vessels. J Med Microbiol 2004;53:259-61.

43. Fergie N, Bayston R, Pearson JP, Birchall JP. Is otitis media with effusion a biofilm infection? Clin Otolaryngol Allied Sci 2004;29:3846.

44. Post JC. Direct evidence of bacterial biofilms in otitis media. Laryngoscope 2001;111:2083-94.

45. Domingue GJ Sr, Hellstrom WJ. Prostatitis. Clin Microbiol Rev 1998;11:604-13.

46. Lamont RJ, El-Sabaeny A, Park Y, Cook GS, Costerton JW, Demuth DR. Role of the Streptococcus gordonii SspB protein in the development of Porphyromonas gingivalis biofilms on streptococcal substrates. Microbiology 2002;148:1627-36.

47. Haffajee AD, Arguello El, Ximenez-Fyvie LA, Socransky SS. Controlling the plaque biofilm. Int Dent J 2003;53 Suppl 3:191-9.

48. Eckert LO, Moore DE, Patton DL, Agnew KJ, Eschenbach DA. Relationship of vaginal bacteria and inflammation with conception and early pregnancy loss following in-vitro fertilization. Infect Dis Obstet Gynecol 2003;11:11-7.

49. Hotchkiss RS, Karl IE. The pathophysiology and treatment of sepsis. N Engl J Med 2003;348:138-50.

50. Barton GM, Medzhitov R. Toll-like receptor signaling pathways. Science 2003;300:1524-5.

51. Medzhitov R, Janeway C Jr. Innate immune recognition: mechanisms and pathways. Immunol Rev 2000;173:89-97.

52. Fazeli A, Bruce C, Anumba DO. Characterization of Toll-like receptors in the female reproductive tract in humans. Hum Reprod 2005;20:1372-8.

53. Kim YM, Romero R, Chaiworapongsa T, Kim GJ, Kim MR, Kuivaniemi $\mathrm{H}$, et al. Toll-like receptor-2 and -4 in the chorioamniotic membranes in spontaneous labor at term and in preterm parturition that are associated with chorioamnionitis. Am J Obstet Gynecol 2004;191:1346-55.

54. Abrahams VM, Bole-Aldo P, Kim YM, Straszewski-Chavez SL, Chaiworapongsa T, Romero R, et al. Divergent trophoblast responses to bacterial products mediated by TLRs. J Immunol 2004;173:4286-96.

55. Jin LP, Fan DX, Zhang T, Guo PF, Li DJ. The costimulatory signal upregulation is associated with Th1 bias at the maternal-fetal interface in human miscarriage. Am J Reprod Immunol 2011;66: 270-8.

56. Guzeloglu-Kayisli O, Kayisli UA, Taylor HS. The role of growth factors and cytokines during implantation: endocrine and paracrine interactions. Semin Reprod Med 2009;27:62-79.

57. Kitaya K, Nakayama T, Okubo T, Kuroboshi H, Fushiki S, Honjo H. 
Expression of macrophage inflammatory protein-1beta in human endometrium: its role in endometrial recruitment of natural killer cells. J Clin Endocrinol Metab 2003;88:1809-14.

58. Jones RL, Hannan NJ, Kaitu'u TJ, Zhang J, Salamonsen LA. Identification of chemokines important for leukocyte recruitment to the human endometrium at the times of embryo implantation and menstruation. J Clin Endocrinol Metab 2004;89:6155-67.

59. Fowler DJ, Nicolaides KH, Miell JP. Insulin-like growth factor binding protein-1 (IGFBP-1): a multifunctional role in the human female reproductive tract. Hum Reprod Update 2000;6:495-504.

60. Matteo M, Cicinelli E, Greco P, Massenzio F, Baldini D, Falagario T, et al. Abnormal pattern of lymphocyte subpopulations in the endometrium of infertile women with chronic endometritis. Am J Reprod Immunol 2009;61:322-9.

61. Bulmer JN, Williams PJ, Lash GE. Immune cells in the placental bed. Int J Dev Biol 2010;54:281-94.

62. Tortorella C, Piazzolla G, Matteo M, Pinto V, Tinelli R, Sabba C, et al. Interleukin-6, interleukin-1 $\beta$, and tumor necrosis factor $a$ in menstrual effluents as biomarkers of chronic endometritis. Fertil Steril 2014;101:242-7.

63. Kamiyama S, Teruya Y, Nohara M, Kanazawa K. Bacterial endotoxin in the endometrium and its clinical significance in reproduction. Fertil Steril 2004;82:805.

64. Shahzad S. Investigation of the prevalence of female genital tract tuberculosis and its relation to female infertility: an observational analytical study. Iran J Reprod Med 2012;10:581-8.

65. Ulusoy AN, Karabicak I, Dicle K, Kefeli M, Tosun M, Cetinkaya M, et al. Peritoneal tuberculosis in premenopausal patients with elevated serum CA 125. Arch Gynecol Obstet 2010;282:639-42.

66. Di Pietro C, Cicinelli E, Guglielmino MR, Ragusa M, Farina M, Palumbo MA, et al. Altered transcriptional regulation of cytokines, growth factors, and apoptotic proteins in the endometrium of infertile women with chronic endometritis. Am J Reprod Immunol 2013;69:509-17.

67. Fazleabas AT, Kim JJ, Strakova Z. Implantation: embryonic signals and the modulation of the uterine environment. A review. Placenta 2004;25 Suppl A:S26-31.

68. Lathi RB, Hess AP, Tulac S, Nayak NR, Conti M, Giudice LC. Dosedependent insulin regulation of insulin-like growth factor binding protein-1 in human endometrial stromal cells is mediated by distinct signaling pathways. J Clin Endocrinol Metab 2005;90: 1599-606.

69. Dimitriadis E, White CA, Jones RL, Salamonsen LA. Cytokines, chemokines and growth factors in endometrium related to implantation. Hum Reprod Update 2005;11:613-30.

70. von Rango U, Alfer J, Kertschanska S, Kemp B, Muller-Newen G, Heinrich PC, et al. Interleukin-11 expression: its significance in eutopic and ectopic human implantation. Mol Hum Reprod 2004;10:783-92.

71. Dimitriadis E, Robb L, Liu YX, Enders AC, Martin H, Stoikos C, et al. IL-11 and IL-11Ralpha immunolocalisation at primate implantation sites supports a role for IL-11 in placentation and fetal development. Reprod Biol Endocrinol 2003;1:34.

72. Fest S, Aldo PB, Abrahams VM, Visintin I, Alvero A, Chen R, et al. Trophoblast-macrophage interactions: a regulatory network for the protection of pregnancy. Am J Reprod Immunol 2007;57:5566.

73. Maybin JA, Critchley HO, Jabbour HN. Inflammatory pathways in endometrial disorders. Mol Cell Endocrinol 2011;335:42-51.

74. Kitaya K, Yasuo T. Aberrant expression of selectin E, CXCL1, and CXCL13 in chronic endometritis. Mod Pathol 2010;23:1136-46.

75. Pickartz H, Beckmann R, Fleige B, Due W, Gerdes J, Stein H. Steroid receptors and proliferative activity in non-neoplastic and neoplastic endometria. Virchows Arch A Pathol Anat Histopathol 1990;417:163-71.

76. Mishra K, Wadhwa N, Guleria K, Agarwal S. ER, PR and Ki-67 expression status in granulomatous and chronic non-specific endometritis. J Obstet Gynaecol Res 2008;34:371-8.

77. Ness RB, Soper DE, Holley RL, Peipert J, Randall H, Sweet RL, et al. Effectiveness of inpatient and outpatient treatment strategies for women with pelvic inflammatory disease: results from the Pelvic Inflammatory Disease Evaluation and Clinical Health (PEACH) randomized trial. Am J Obstet Gynecol 2002;186:929-37.

78. Johnston-MacAnanny EB, Hartnett J, Engmann LL, Nulsen JC, Sanders MM, Benadiva CA. Chronic endometritis is a frequent finding in women with recurrent implantation failure after in vitro fertilization. Fertil Steril 2010;93:437-41.

79. Kitaya K, Tada Y, Taguchi S, Funabiki M, Hayashi T, Nakamura Y. Local mononuclear cell infiltrates in infertile patients with endometrial macropolyps versus micropolyps. Hum Reprod 2012;27: 3474-80.

80. Barash A, Dekel N, Fieldust S, Segal I, Schechtman E, Granot I. Local injury to the endometrium doubles the incidence of successful pregnancies in patients undergoing in vitro fertilization. Fertil Steril 2003;79:1317-22.

81. Demirol A, Gurgan T. Effect of treatment of intrauterine pathologies with office hysteroscopy in patients with recurrent IVF failure. Reprod Biomed Online 2004;8:590-4.

82. Makrakis E, Pantos K. The outcomes of hysteroscopy in women with implantation failures after in-vitro fertilization: findings and effect on subsequent pregnancy rates. Curr Opin Obstet Gynecol 2010;22:339-43.

83. Gibreel A, El-Adawi N, Elgindy E, Al-Inany H, Allakany N, Tournaye $\mathrm{H}$. Endometrial scratching for women with previous IVF failure 
undergoing IVF treatment. Gynecol Endocrinol 2015;31:313-6.

84. Almog B, Shalom-Paz E, Dufort D, Tulandi T. Promoting implantation by local injury to the endometrium. Fertil Steril 2010;94: 2026-9.

85. Bosteels J, Weyers S, Puttemans P, Panayotidis C, Van Herendael B, Gomel V, et al. The effectiveness of hysteroscopy in improving pregnancy rates in subfertile women without other gynaecological symptoms: a systematic review. Hum Reprod Update 2010;16:1-11.

86. Simon C, Bellver J. Scratching beneath 'The Scratching Case': sys- tematic reviews and meta-analyses, the back door for evidencebased medicine. Hum Reprod 2014;29:1618-21.

87. Di Spiezio Sardo A, Di Carlo C, Minozzi S, Spinelli M, Pistotti V, Alviggi $C$, et al. Efficacy of hysteroscopy in improving reproductive outcomes of infertile couples: a systematic review and metaanalysis. Hum Reprod Update 2016;22:479-96.

88. Lensen SF, Manders M, Nastri CO, Gibreel A, Martins WP, Templer $\mathrm{GE}$, et al. Endometrial injury for pregnancy following sexual intercourse or intrauterine insemination. Cochrane Database Syst Rev 2016;(6):CD011424. 